\title{
Formulation and Evaluation of Bilayer Tablets of Glimepiride and Metformin HCL
}

\author{
Pamu. Sandhya ${ }^{1,2}$, Faheem Unnisa Begum ${ }^{1}$, Afreen $^{1}$ \\ ${ }^{I}$ Department of Pharmaceutics, Shadan Womens College of Pharmacy, 500 004, Hyderabad, India \\ ${ }^{2}$ University College of Technology, Osmania University, Hyderabad, 500 007, India
}

\begin{abstract}
The objective of the present investigation was to prepare bilayer tablets of Glimepride and Metformin HCL in combination. Metformin hydrochloride and Glimepiride are oral hypoglycemic drug and effectively used in treatment of diabetes mellitus (type-2 diabetes). The main aim of the present study was to formulate Metformin hydrochloride sustained release and Glimepride immediate release matrix tablets as a dosage form by different polymers such as HPMC, Povidone, Lactose Monohydrate, Ethylcellulose, Microcrystalline Cellulose and study the invitro release patterns of the drug. In the present study bilayer tablets Glimepride prepared by direct compression method and Metformin prepared by wet granulation technology. The prepared tablets were evaluated for various physicochemical parameters such as drug-excipient interaction by FTIR,flow properties, hardness, weight variation, friability, and in vitro dissolution studies optimised based on desired sustained release time (16hrs) and acceptable floating properties The FTIR study revealed that there is no drug-excipient interaction. During preformulation it has been observed that there is no drugdrug and drug excipient interaction, so the excipients which have been selected for the formulation are compatible with the drugs. This system provides zero order or near zero order release for IR layer and SR layer provides Higuchi model.
\end{abstract}

Keywords: Glimepiride, Metformin HCL, Oral controlled release drug delivery system, HPMC

Tablets $^{[1,4]}$

\section{Introduction}

Pharmaceutical tablets are the dominant dosage forms for drug delivery, occupying two thirds of the global market. Generally, they are formulated by compressing dry powder blends consisting of a number of components with different functionalities in a die.

\section{Multilayered tablets}

Layered tablet consists of two or more layers of granulation compressed together. This dosage form has the advantage of separating two incompatible substances. It comprises several different granulations that are compressed to form a single tablet composed of two or more layers and usually each layer is of different colour to produce a distinctive looking tablet. Each layer is fed from distinct feed frame with individual weight control.

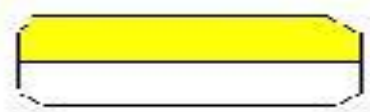

Fig 1: Bilayered Tablet

Definition ${ }^{[6]}$

Dual release tablet is a unit compressed tablet dosage form intended for oral application. It contains two parts in which one part having conventional or immediate release part another one is sustained or controlled release part.

\section{Diabetes mellitus}

Diabetes mellitus is a metabolic disorder characterized by hyperglycemia, glycosuria, hyperlipemia, negative nitrogen balance and sometimes ketonemia. A wide spread pathological change in thickening of capillary basement membrane, increase in vessel wall matrix and cellular proliferation resulting in vascular complications like lumen narrowing, early atherosclerosis, sclerosis of glomerular capillaries, retinopathy, neuropathy and peripheral vascular insufficiency. 


\section{Literature Review}

Uttam Mandal et al. designed an oral sustained release sustained matrix tablet of Metformin $\mathrm{HCl}$ and optimizes the drug profile using response surface methodology. The tablets were formulated by non aqueous wet granulation method using HPMC K $15 \mathrm{M}$ as matrix forming polymer. HPMC K15M and PVP were taken as the independent variables.

Asha Patel et al. developed controlled release floating drug delivery system of Metformin $\mathrm{HCl}$ microspheres by non-aqueous emulsification solvent evaporation technique using ethylcellulose as the rate controlling polymer and $250 \mathrm{mg}$ of Metformin hydrochloride. The experimental design supported product development and optimization procedure yielded the desired microspheres with drug release equivalent to those of the marketed single unit dosage forms with the added advantage of floatability in gastric juice for prolonged slow release.

Cananersoya et al. studied the effect of Metformin on markers of endothelial function, vascular inflammation and factors of thrombosis in obese type 2 diabetic patients. 24 type II diabetic patients (15 female and 9 male) which was previously under medical nutrition treatment (MNT) + regular exercise programme (REP) without chronic micro or macrovascular complications with the mean age of $50.5 \pm 1.5$ years, diabetes duration of $17.9 \pm 6.3$ months and body mass index (BMI) of $31.7 \pm 0.8 \mathrm{~kg} / \mathrm{m}^{2}$ were enrolled in the study.

Subramaniam Kannan et al.performed for the formulation and evaluation of sustained release tablets of Aceclofenac using hydrophilic matrix system to develop once daily sustained release tablets of Aceclofenac (200mg) by wet granulation using hydrophilic polymer like hydroxypropyl methyl cellulose K-100. The drug excipients mixtures were subjected to preformulation studies. The tablets were subjected to physicochemical studies, in-vitrodrug release, kinetic studies and stability studies.

\section{Materials \& Methodology}

\section{Table 1: Materials}

\begin{tabular}{|c|l|}
\hline S. No. & \multicolumn{1}{|c|}{ Materials } \\
\hline 1 & Metformin HCl IP \\
\hline 2 & Glimepiride USP \\
\hline 3 & Ethylcellulose N 14 \\
\hline 4 & HPMC K100 M USP \\
\hline 5 & Microcrystalline cellulose pH 102 \\
\hline 6 & Sodium starch glycolate \\
\hline 7 & Povidone IP (K-30) \\
\hline 8 & Lactose IP (Monohydrate) \\
\hline 9 & Magnesium stearate \\
\hline
\end{tabular}

\section{Drug-Excipient Compatibility Studies by FTIR Spectroscopy}

In the present study, the potassium bromide disc (pellet) method was employed. Fourier-transform infrared (FTIR) spectra of the Drug and polymer were obtained on Alpha Brooker FTIR (Tokyo, Japan). The spectra were scanned over the wave number range of 4000 to $400 \mathrm{~cm}-$.

\section{Preparation of matrix tablets}

For IR layer (Glimepiride) by direct compression method

For SR layer (Metformin $\mathrm{HCl}$ ) by wet granulation method

Table 2: Composition of formulations of Glimepride IR layer

\begin{tabular}{|c|c|c|c|c|c|c|c|c|c|}
\hline \multirow{2}{*}{ Ingredients } & \multicolumn{8}{|c|}{ Content (mg/tablet) } & \multirow[b]{2}{*}{ F9 } \\
\hline & $\mathrm{F} 1$ & $\mathrm{~F} 2$ & F3 & $\mathrm{F} 4$ & F5 & F6 & F7 & F8 & \\
\hline Glimepiride & 5 & 5 & 5 & 5 & 5 & 5 & 5 & 5 & 5 \\
\hline MCC 102 & 63.5 & 50 & 77 & 40 & 45 & 65 & 47 & 80 & 37 \\
\hline Lactose & 63.5 & 77 & 50 & 87 & 82 & 62 & 80 & 47 & 90 \\
\hline SSG & 9 & 9 & 9 & 9 & 9 & 9 & 9 & 9 & 9 \\
\hline Povidone & 6 & 6 & 6 & 6 & 6 & 6 & 6 & 6 & 6 \\
\hline Magnesium Stearate & 3 & 3 & 3 & 3 & 3 & 3 & 3 & 3 & 3 \\
\hline Total tablet weight (mg) & 150 & 150 & 150 & 150 & 150 & 150 & 150 & 150 & 150 \\
\hline
\end{tabular}

Table 3: Composition of formulations of Metformin SR layer

\begin{tabular}{|c|c|c|c|c|c|c|c|c|}
\hline \multirow[b]{2}{*}{ Ingredients } & \multicolumn{6}{|c|}{ Content (mg/tablet) } & \multirow[b]{2}{*}{ F7 } & \multirow[b]{2}{*}{ F8 } \\
\hline & $\mathrm{F} 1$ & $\mathrm{~F} 2$ & F3 & F4 & F5 & F6 & & \\
\hline Metformin HCL & 500 & 500 & 500 & 500 & 500 & 500 & 500 & 500 \\
\hline MCC 102 & 204 & 172 & 140 & 108 & 204 & 172 & 140 & 108 \\
\hline
\end{tabular}


Formulation And Evaluation Of Bilayeer Tablets Of Glimepiride And Metformin Hcl

\begin{tabular}{|c|c|c|c|c|c|c|c|c|}
\hline & & & & & & & & - \\
\hline Ethylcellulose N50 & 64 & 96 & 128 & 160 & -- & -- & - & 160 \\
\hline HPMC k100m & -- & -- & -- & -- & 64 & 96 & 128 & 24 \\
\hline Povidone & 24 & 24 & 24 & 24 & 24 & 24 & 24 \\
\hline Magnesium Stearate & 8 & 8 & 8 & 8 & 8 & 8 & 8 & 8 \\
\hline IPA & q.s & q.s & q.s & q.s & q.s & q.s & q.s & q.s \\
\hline Total tablet weight (mg) & 800 & 800 & 800 & 800 & 800 & 800 & 800 & 800 \\
\hline
\end{tabular}

Evaluation of matrix tablets:

\section{Post compression parameters:}

The prepared tablets were evaluated for General appearance, thickness, hardness, weight variation, friability and uniformity of weight.

\section{Stability Studies:}

The optimized matrix tablets were subjected to stability studies(as per ICH guide lines) at $25^{\circ} \mathrm{C} \pm 2{ }^{\circ} \mathrm{C} / 60 \% \pm$ $5 \% \mathrm{RH}$ and $40^{\circ} \mathrm{C} \pm 2{ }^{\circ} \mathrm{C} / 75 \% \pm 5 \% \mathrm{RH}$ The products were evaluated for their physical characteristics, drug content, and In-vitro drug release profiles over a period of 3 months.

\section{Pre formulation Study}

\section{Results}

Ultraviolet Visible (UV-visible) spectroscopy

Drug sample showed wavelength of maximum absorption ( $\lambda$-max) $228 \mathrm{~nm}$ (Glimepride) and $233 \mathrm{~nm}$ (Metformin $\mathrm{HCl}$ ).

Calibration curve of Glimepiride in phosphate buffer pH 1.2 and 6.8

Wavelength of maximum absorption: $228 \mathrm{~nm}$ and $233 \mathrm{~nm}$ respectively.

\section{Evaluation of Blend}

Table Bulk density, Tapped density, \% Compressibility index, Hausner ratio and Angle of repose

Table 4: Post compression parameters

\begin{tabular}{|c|c|c|c|c|c|}
\hline Formulation & Weight variation & $\begin{array}{c}\text { Hardness } \\
\left(\mathrm{K.g} / \mathrm{cm}^{2}\right)\end{array}$ & $\begin{array}{c}\text { Friability } \\
(\%)\end{array}$ & $\begin{array}{c}\text { Thickness } \\
(\mathrm{mm})\end{array}$ & Content uniformity \\
\hline F1 & $951 \pm 0.61$ & $6.4 \pm 0.30$ & $0.72 \pm 0.12$ & $6.8 \pm 0.02$ & $99.28 \pm 0.21$ \\
\hline F2 & $952 \pm 0.54$ & $6.3 \pm 0.20$ & $0.68 \pm 0.08$ & $6.9 \pm 0.08$ & $97.16 \pm 0.17$ \\
\hline F3 & $948 \pm 0.91$ & $6.7 \pm 0.25$ & $0.69 \pm 0.09$ & $6.8 \pm 0.06$ & $101.18 \pm 0.14$ \\
\hline F4 & $949 \pm 0.58$ & $6.6 \pm 0.10$ & $0.66 \pm 0.15$ & $6.8 \pm 0.04$ & $97.68 \pm 0.23$ \\
\hline F5 & $951 \pm 0.46$ & $6.7 \pm 0.40$ & $0.68 \pm 0.14$ & $6.8 \pm 0.01$ & $99.41 \pm 0.10$ \\
\hline F6 & $948 \pm 0.23$ & $6.9 \pm 0.25$ & $0.65 \pm 0.06$ & $6.7 \pm 0.02$ & $98.19 \pm 0.17$ \\
\hline F7 & $950 \pm 0.53$ & $7.2 \pm 0.30$ & $0.67 \pm 0.08$ & $6.8 \pm 0.04$ & $102.6 \pm 0.12$ \\
\hline F8 & $952 \pm 0.42$ & $7.1 \pm 0.10$ & $0.68 \pm 0.16$ & $6.9 \pm 0.06$ & $99.31 \pm 0.21$ \\
\hline
\end{tabular}

In -vitro drug release study

Table 5: Cumulative \%drug released formulations of Glimepiride IR layer

\begin{tabular}{|c|c|c|c|}
\hline Formulation & $5 \mathrm{~min}$ & $10 \mathrm{~min}$ & $15 \mathrm{~min}$ \\
\hline F1 & 33.97 & 60.07 & 82.55 \\
\hline F2 & 37.54 & 60.37 & 84.98 \\
\hline F3 & 39.33 & 60.79 & 86.34 \\
\hline F4 & 39.33 & 65.43 & 88.82 \\
\hline F5 & 50.06 & 77.61 & 88.64 \\
\hline
\end{tabular}




\begin{tabular}{|c|c|c|c|}
\hline F6 & 51.85 & 85.82 & 98.44 \\
\hline F7 & 28.6 & 48.27 & 91.52 \\
\hline F8 & 26.82 & 62.58 & 93.82 \\
\hline F9 & 32.18 & 60.79 & 92.9 \\
\hline
\end{tabular}

The dissolution profile of Glimepride IR layer was given in graphical representation, the formulation F6 showed maximum drug release, hence F6 was best formula and F6 IR layer was compressed with Metformin SR layers (Table 5, Fig 2).

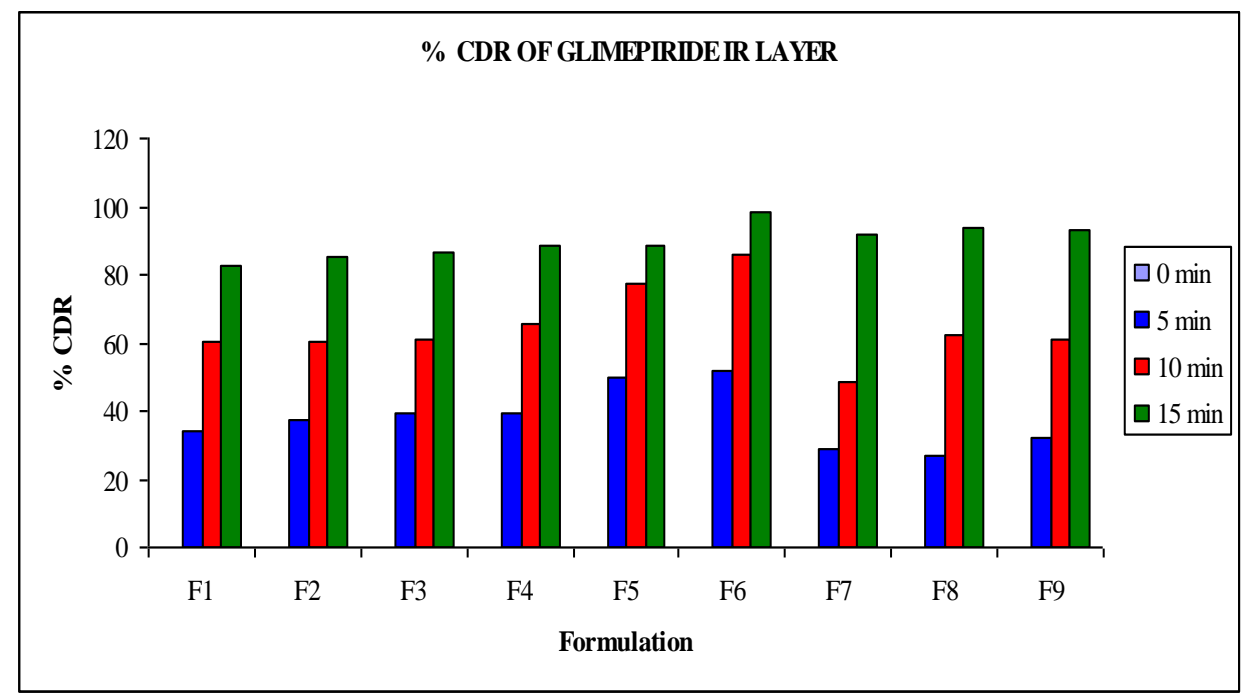

Fig 2: Cumulative \%drug released formulations of Glimepiride IR layer

For SR layer Metformin HCl

Table 6: Cumulative \%drug released formulations of Metformin HCI SR layer

\begin{tabular}{|c|c|c|c|c|c|c|c|}
\hline Form.n & $1.5 \mathrm{hr}$ & $3 \mathrm{hr}$ & $4 \mathrm{hr}$ & $6 \mathrm{hr}$ & $8 \mathrm{hr}$ & $10 \mathrm{hr}$ & $12 \mathrm{hr}$ \\
\hline F1 & 30.96 & 56.87 & 76.8 & 96.47 & - & - & - \\
\hline F2 & 26.54 & 37.04 & 50.74 & 75.46 & 94.12 & - & - \\
\hline F3 & 23.4 & 34.44 & 42.96 & 56.31 & 72.89 & 91.24 & - \\
\hline F4 & 18.4 & 21.3 & 34.89 & 47.1 & 64.31 & 82.97 & 86.47 \\
\hline F5 & 36.29 & 46.3 & 79.86 & 94.66 & - & - & - \\
\hline F6 & 28.64 & 33.5 & 45.98 & 70.64 & 94.68 & - & - \\
\hline F7 & 24.92 & 32.84 & 48.23 & 68.91 & 78.61 & 95.87 & - \\
\hline F8 & 20.14 & 31.8 & 54.44 & 66.67 & 72.22 & 82.54 & 98.63 \\
\hline
\end{tabular}

The dissolution profile of Metformin SR layer was given in graphical representation, the formulation F8 was best among the all formulations (Table 6, Fig 3).

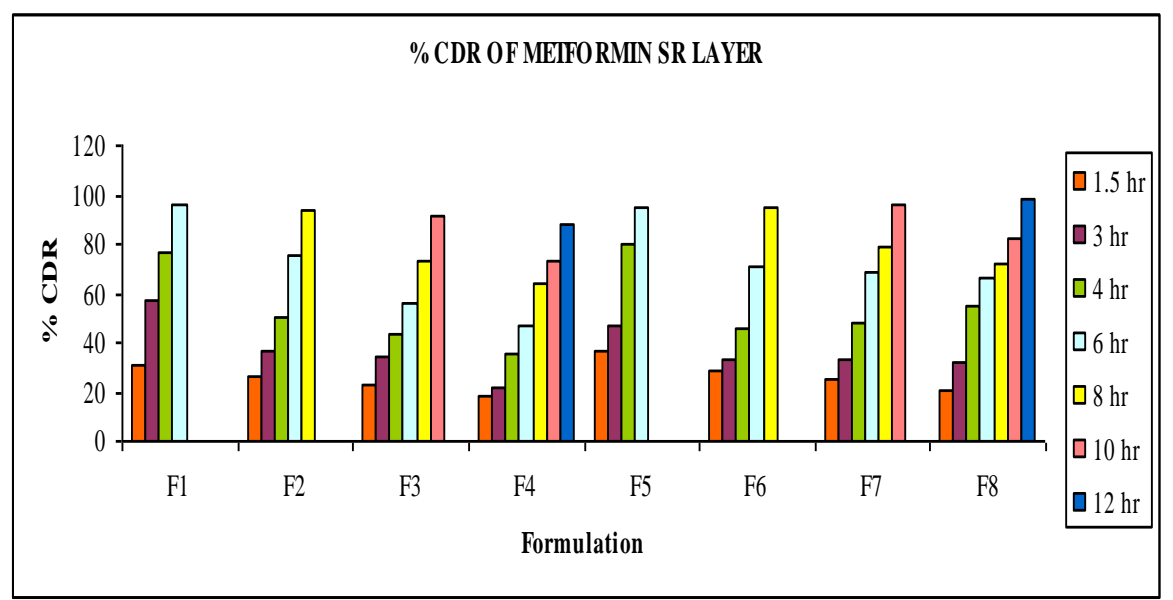

Fig 3: Cumulative \%drug released formulations of Metformin HCl SR layer 
Model -Dependent Approaches:

Zero order Release for IR layer

Table 7: Zero order plot of F6 of Glimepiride IR layer

\begin{tabular}{|c|c|}
\hline TIME $(\min )$ & cumulative \% drug release \\
\hline 5 & 51.85 \\
\hline 10 & 85.82 \\
\hline 15 & 98.54 \\
\hline
\end{tabular}

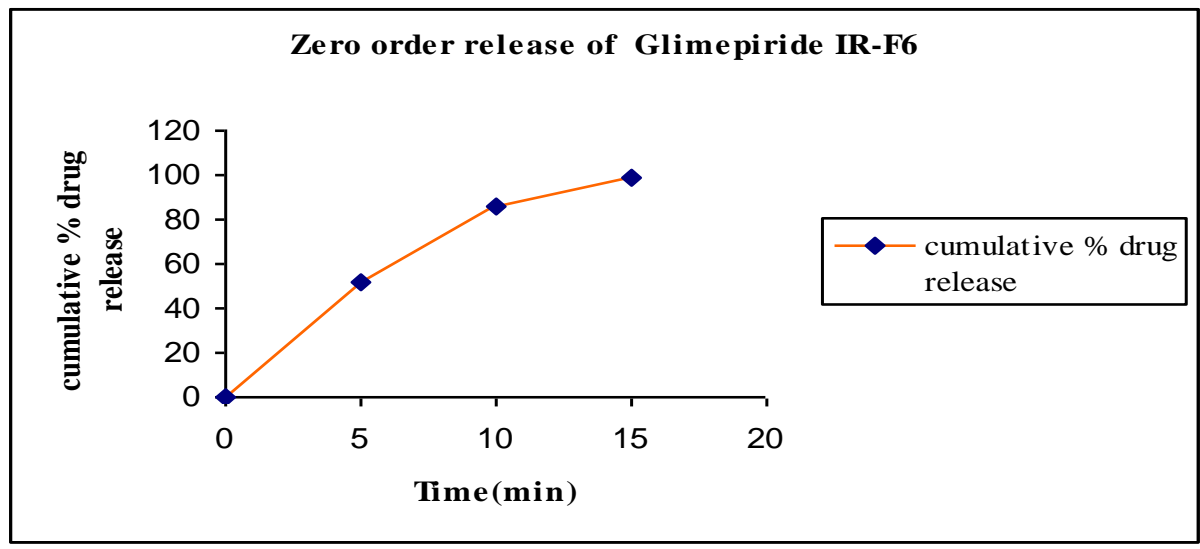

Fig 4: Zero order plot for Glimepiride IR- F6 Formulation

Table 8: First order plot of F6 Formulation (IR layer)

\begin{tabular}{|c|c|}
\hline TIME (hrs) & Log cumulative \% drug remaining \\
\hline 5 & 1.714 \\
\hline 10 & 1.933 \\
\hline 15 & 1.993 \\
\hline
\end{tabular}

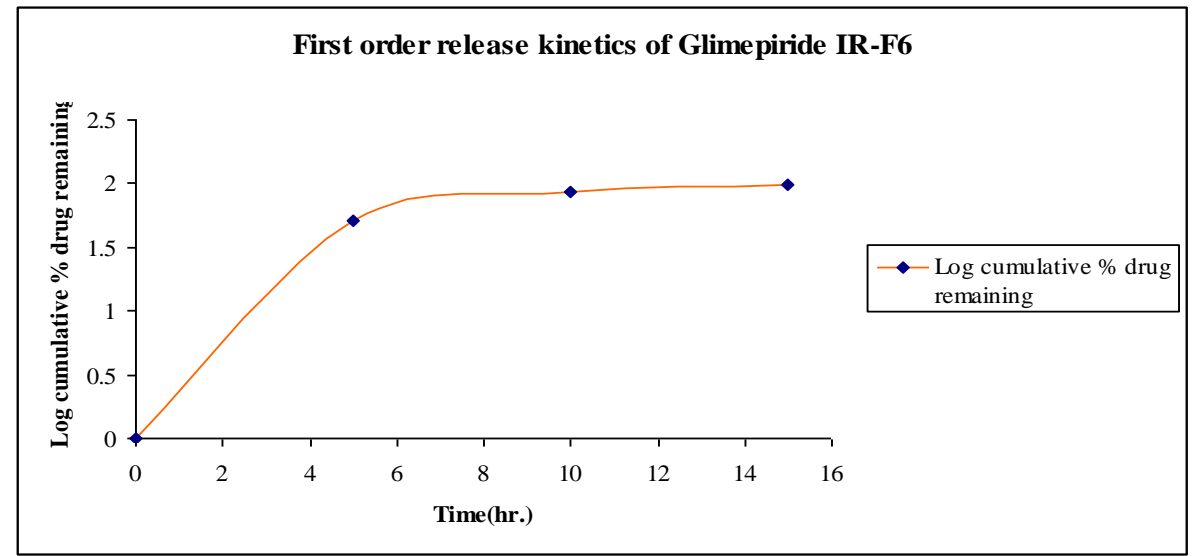

Fig. 5: First order release kinetics of Glimepiride F6

Zero Order Release for SR layer 
Table 9: Zero order plots for F8 of Metformin HCL

\begin{tabular}{|c|c|c|c|c|c|c|c|}
\hline Time in hrs & 1.5 & 3 & 4 & 6 & 8 & 10 & 12 \\
\hline$\%$ CDR & 20.14 & 31.8 & 54.44 & 66.67 & 72.22 & 82.54 & 98.63 \\
\hline
\end{tabular}

First Order Release for SR layer

Table 10: First order plot of F8 of Metformin HCl

\begin{tabular}{|c|c|c|c|c|c|c|c|}
\hline Time hrs & 1.5 & 3 & 4 & 6 & 8 & 10 & 12 \\
\hline Log \% remaining & 1.902 & 1.833 & 1.658 & 1.522 & 1.443 & 1.242 & 0.136 \\
\hline
\end{tabular}

\section{Higuchi Model for SR layer}

Table 11: Higuchi model of $\mathrm{F8}$ formulation Metformin $\mathrm{HCl}$

\begin{tabular}{|c|c|c|c|c|c|c|c|}
\hline SQRT & 1.2 & 1.7 & 2 & 2.4 & 2.8 & 3.1 & 3.4 \\
\hline$\% \mathrm{CDR}$ & 20.14 & 31.8 & 54.44 & 66.67 & 72.22 & 82.54 & 98.63 \\
\hline
\end{tabular}

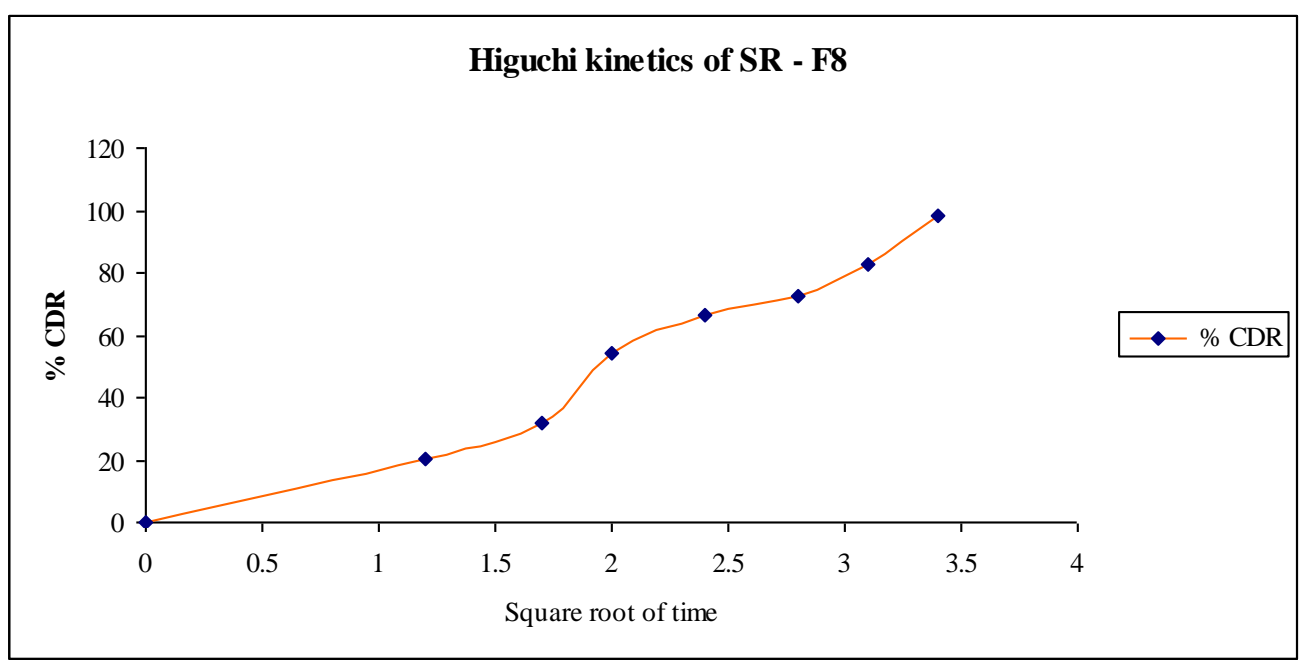

Fig 6: Higuchi model for F8 Metformin HCl

Korsmeyer Peppas plot for SR layer

Table 12: Korsmeyer Peppas model of F8 Metformin HCl

\begin{tabular}{|c|c|c|c|c|c|c|c|}
\hline $\log \mathrm{T}$ & 0.176 & 0.477 & 0.602 & 0.778 & 0.903 & 1 & 1.079 \\
\hline $\log \% \mathrm{CDR}$ & 1.304 & 1.502 & 1.735 & 1.823 & 1.858 & 1.916 & 1.994 \\
\hline
\end{tabular}

Dissolution kinetic parameters of Metformin Hcl

According to above $\mathrm{R}^{2}$ value, best formulation, i.e, F8 formulation follows higuchi's model which shows that drug is released from matrix (Table 11, Fig 6).

\section{Stability Studies}

There was no significant change in physical and chemical properties of the tablets of formulation F8 after 3 Months (Table 13).

Table 13: Results of stability studies of optimized formulation F8 Metformin HCl

\begin{tabular}{|c|l|l|l|l|l|l|}
\hline S. NO & Parameters & Initial & 1 month & 2 month & 3 month & $\begin{array}{l}\text { Limts as per } \\
\text { specification }\end{array}$ \\
\hline 1 & $\begin{array}{l}400 \mathrm{C} / 75 \% \mathrm{RH} \\
\% \text { Release }\end{array}$ & 98.63 & 98.22 & 98.01 & 97.62 & $\begin{array}{c}\text { Not less than } \\
85 \%\end{array}$ \\
\hline 2 & $\begin{array}{l}400 \mathrm{C} / 75 \% \mathrm{RH} \\
\text { Assay Value }\end{array}$ & 98.31 & 98.28 & 98.22 & 98.17 & $\begin{array}{c}\text { Not less than } \\
90 \% \\
\text { Not more than } \\
110 \%\end{array}$ \\
\hline
\end{tabular}




\section{Discussion}

In the present study an attempt has been to formulate and evaluate sustained release matrix tablets of Metformin $\mathrm{HCl}$ and Glimepride IR layer, employing swellable polymers like Hydroxy propyl methylcellulose(HPMC K100M), Xanthan gum and synthetic polymer Ethylcellulose N-50, Eudragit RS100 were taken along with pharmaceutically acceptable easily available inert excipients and nine formulations were prepared. The formulation was subjected to both pre and post formulation studies. The procured drug sample of Glimepiride and Metformin $\mathrm{HCl}$ was tested for its identification by means of organoleptic properties, melting point, UV spectra and FTIR spectrum.

\section{UV Spectroscopic Analytical Method}

Standard curve of Glimepiride and Metformin $\mathrm{HCl}$ were taken in $\mathrm{pH} 1.2$, wavelengths of maximum absorption was found to be $228 \mathrm{~nm}$ and $233 \mathrm{~nm}$ respectively. The Glimepiride obeyed the Lambert-Beer's law in concentration range of $1-10 \mu \mathrm{g} / \mathrm{ml}$ and Metformin obeyed the Lambert-Beer's law at this wavelength. This is well correlated with the reported value (228nm and $233 \mathrm{~nm})$.

\section{Drug Interaction Study}

FTIR spectra of Metformin $\mathrm{HCl}$ and physical mixture of Metformin HCL and polymers (HPMC K100ME and EC) were taken. All the characteristic peaks of pure drug were observed in the spectrum of mixture. This indicated that there was not any interaction between drug and polymer.

The granules prepared by wet granulation method were evaluated for various flow properties for SR layer of Metformin $\mathrm{HCl}$.

\section{Physical characterization of Bilayer Tablets of Glimepiride and Metformin HCl}

Tablet thickness, hardness, weight variation, friability and drug content of formulated tablets of batches from F1 to F9 for IR layer and F1 to F8 for SR layer are presented in Table 4.

\section{Uniformity of weight}

All the prepared Bilayer tablets of Glimepiride and Metformin $\mathrm{HCl}$ were evaluated for weight variation. The weight of all the tablets was found to be uniform with low values of standard deviation and within the prescribed IP limits of $\pm 7.5 \%$ (Table 4).

\section{Hardness and friability}

The hardness of the tablet formulations was found to be in the range of 6.3 to $7.2 \mathrm{~kg} / \mathrm{cm}^{2}$. The friability values were found to be in the range of 0.65 to $0.72 \%$ (Table 4).

\section{Uniformity of drug content}

Percent drug content of all the tablets was found to be in the range of 97.16 to 102.6 percent (which was within the acceptable limits of $\pm 5 \%$ ) (Table 4 ).

\section{In vitro dissolution study}

In vitro dissolution studies were performed for IR, SR layers, the results are shown in Table 5, 6. In the dissolution studies the HPMCK100M, Xanthan gum and Ethylcellulose and Eudragit polymers were showing better drug release up to $12 \mathrm{hrs}$.

\section{Model-Dependent Approaches \\ Release Kinetics}

To know the drug release kinetics from these formulations, the dissolution data were subjected to different kinetic model such as Zero order and Higuchi's square root kinetics model. The line of equations and regression coefficient of kinetic study for all the formulations are shown in Table 7, 8, 9, 10, 11 and 12. The regression coefficient was considered as main parameter to interpret release kinetics.

\section{Stability Studies}

There was no significant change in physical and chemical properties of the tablets of formulation F6(Glimepiride) and F8(Metformin $\mathrm{Hcl}$ ) after 3 Months, parameters like \% drug release and assay values at various conditions (at $40^{\circ} \mathrm{C} / 75 \% \mathrm{RH}$ ) as per ICH guidelines quantified at various time intervals were shown in Table 13. 


\section{Conclusion}

This system provides zero order or near zero order release for IR layer and SR layer provides Higuchi model. This concept also demonstrates a wide technology for various applications such as instant release/slow release from one dosage form, because it allows the precise modulation of drug release process even for drug characteristics by extreme physicochemical properties.

\section{References}

[1]. James.Swarbrick. Encyclopedia of pharmaceutical technology, 3rd ed., (2): 1082 (2007).

[2]. www.ondrug delivery.com/ Oral_drug_delivery.

[3]. Kewal.K.Jain. Method in molecular biology 437. Drug delivery system. 217 (2008).

[4]. D M Brahmankar and Sunil B Jaiswal, Biopharmaceutics and pharmacokinetics. A treatise, VallabhPrakashan. 2nd ed., 406 (2009).

[5]. Rajan K. Verma and Sanjay Garg. Current status of drug delivery technologies and future directions, Pharmaceutical technology online. 25 (2): 1-14 (2001)

[6]. Mithul Shah. Sustained release multiple unit dispersible tablet. www.doyouknow.in.

[7]. Loyd V Allen Jr, Nicholas G Popovich, Howard C Ansel. Ansel's Pharmaceutical dosage forms and drug delivery system, 8thed., 54 (2007)

[8]. Sunil Kamboj. Matrix Tablets, An important tool for oral controlled-release dosage forms. http://www.pharmainfo.net.

[9]. K. P. Sampath Kumar, DebjitBhowmik, Chiranjib, Margret Chandira and K. K.Tripathi.Innovations in sustained release drug delivery system and its market opportunities J. Chem. Pharm. Res., 2(1): 349-360 (2010).

[10]. Gilbert S Banker and Christopher T Rhodes, Modern Pharmaceutics. $4^{\text {th }}$ ed., 504 (2002).

[11]. Nandita Das and Sudip K Das. Controlled release of oral dosage forms, formulation, fill and finish, 10-16 (2003). 